\title{
Micro-Unit per Deciliter
}

National Cancer Institute

\section{Source}

National Cancer Institute. Micro-Unit per Deciliter. NCI Thesaurus. Code C124469.

An arbitrary unit of substance content expressed in microunit(s) per deciliter. 